http://ejournal.upi.edu/index.php/jaz - e-mail:_jurnal_zonasi@upi.edu doi.org/10.17509/jaz.v4i2.31609

\title{
ANALISIS FAKTOR KEBETAHAN PENGUNJUNG COFFEE SHOP MELALUI PENILAIAN KINERJA ELEMEN INTERIOR. STUDI KASUS: KAFE DAN COFFEE SHOP DI KAWASAN L.R.E MARTADINATA, BANDUNG.
}

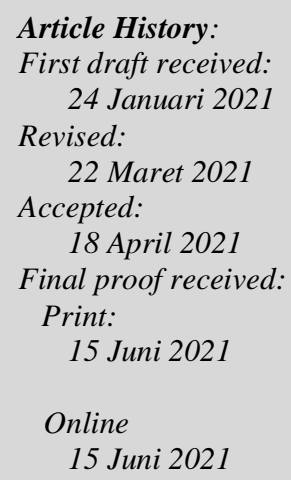

Jurnal Arsitektur ZONASI is indexed and listed in several databases:

SINTA 4 (Arjuna)

GARUDA (Garda Rujukan Digital)

Google Scholar

Dimensions

oneSearch

BASE

Member:
Crossref
RJI
APTARI
FJA (Forum Jurna Arsitektur)
IAI
AJPKM

\author{
Vika Haristianti ${ }^{1}$ \\ M. Togar Mulya Raja ${ }^{2}$ \\ Clarissa Tiara Putri ${ }^{3}$ \\ 1,2,3 Telkom University, Bandung \\ Jl. Telekomunikasi No. 1, Bojongsoang, Sukapura, \\ Kec. Dayeuhkolot, Bandung, Jawa Barat 40257, Indonesia \\ Email: ${ }^{1}$ haristiantivika@telkomuniversity.ac.id
}

\begin{abstract}
This research is aimed to evaluate the performance of interior design elements applied at case studies of cafes and coffee shops. The said performance relates to factors of designs that influence the motivation possibility of frequent visits that can affect the growth of café society to keep rising. This research counts as a pragmatic research or mixed methods. This type of research is chosen because its possibility to collect data and analyze data in a qualitative and quantitative assessment in one study at the same time. The method of collecting data in this research is divided into two which include literature research and field research. The aforementioned data is collected from case studies of cafés and coffee shops residing at L.R.E Martadinata Bandung area, which are Dakken Restaurant and Jardin Café.The result of this research shows that interior elements influences the factors of café visitors' adjustment.
\end{abstract}

Keywords: Adjustment, coffee shop, café society, city space transformation

\begin{abstract}
Abstrak: Penelitian ini bertujuan untuk menilai kinerja dari elemen desain interior yang diterapkan pada kafe dan coffee shop studi kasus. Kinerja yang dimaksud berkaitan dengan faktor desain apa saja yang berpengaruh pada kemungkinan motivasi kunjungan frekuen yang dapat mengakibatkan perkembangan café society terus meningkat. Penelitian ini bersifat penelitian pragmatis atau gabungan yang disebut mixed methods. Jenis penelitian ini dipilih karena memungkinkan untuk dilakukan pengumpulan serta analisis data secara kualitatif dan kuantitatif dalam sebuah studi secara sekaligus. Metode pengumpulan data yang dilakukan pada penelitian ini dibagi menjadi dua yaitu penelitian kepustakaan (secondary sources / pengumpulan data sekunder) dan penelitian lapangan (primary sources/ pengumpulan data primer). Adapun data tersebut diambil dari studi kasus berupa kafe dan coffee shop di kawasan L.R.E Martadinata Bandung, yaitu Dakken Restaurant dan Jardin Café. Hasil penelitian menunjukkan bahwa elemen interior berpengaruh pada faktor kebetahan pengunjung kafe.
\end{abstract}

Kata Kunci: kebetahan, coffee shop, café society, transformasi ruang kota.

\section{Pendahuluan}

Saat ini menjamurnya bisnis kuliner di berbagai daerah telah menjadi sebuah fenomena pada perkembangan gaya hidup masyarakat urban. Dalam satu dekade terakhir, berbagai macam festival serta jenis usaha kuliner seperti kafe, coffee shop, bar and lounge maupun restoran terus bermunculan dengan mengedepankan berbagai kebaruan konsep. Tinamei, 2006 menjelaskan fenomena ini sebagai bagian dari café society. Yaitu jenis gaya hidup urbanisme populer yang bermuara pada pencarian penuh gairah untuk hiburan masyarakat. Kafe dinilai memiliki peran penting dalam menciptakan imej kota, elemen urban, bahkan mampu mendeskripsikan identitas dan tingkatan kelas pada masyarakat. Di Indonesia sendiri, fenomena café society 
saat ini terus tumbuh dan berkembang salah satunya di Bandung yang merupakan ibu kota dari Provinsi Jawa Barat. Fakta bahwa kota ini menempati peringkat keempat sebagai kota dengan populasi terpadat di Indonesia serta dekat dengan Jakarta sebagai pusat perekonomian, berdampak pada gaya hidup masyarakat Bandung yang dinilai cepat beradaptasi terhadap perkembangan yang ada. Hal inipun akhirnya menjadi salah satu faktor penyebab terjadinya transformasi ruang kota di Bandung.

Data statistik tahun 2018 dari Dinas Kebudayaan dan Pariwisata Kota Bandung mencatat jumlah bisnis kuliner yang terdaftar mencapai 795 buah, yang mana jika melihat dari perkembangan dua tahun terakhir jumlah ini diprediksi telah meningkat. Peningkatan tersebut merupakan akibat dari berkembangnya fenomena café society di atas yang secara spesifik pula telah diakibatkan salah satunya oleh kemajuan pesat coffee culture di Bandung. Beberapa kawasan terus mengalami transformasi informal salah satunya di sekitar kawasan L.R.E Martadinata atau lebih dikenal sebagai Jalan Riau yang dianggap memiliki lokasi yang strategis dan mudah untuk dijadikan lokasi berkumpul. Menjadikan kafe dan coffee shop sebagai sarana berkumpul dan menghabiskan waktu, masyarakat dari berbagai kalangan dan usia saat ini sangat gemar meminum kopi sambil berbincang maupun beraktivitas di coffe shop dan kafe. Adanya fenomena lain berupa kegandrungan masyarakat terhadap media sosial dan fotografi juga turut membuat café society lebih berkembang. Sifat masyarakat yang kerap menggunakan media sosial untuk berbagi tentang kehidupan pribadi dalam lingkaran pertemanan guna menunjukkan eksistensi diri menjadi salah satu alasan lain untuk secara frekuen datang dan berinteraksi di sebuah kafe (Haristianti, 2016).

Adapun kunjungan frekuen pada sebuah kafe dan coffee shop merupakan akibat dari rasa kebetahan. Kebetahan merupakan kondisi psikologis di mana manusia merasa nyaman dan puas pada suatu tempat sehingga senang untuk tinggal berlama-lama pada tempat tersebut. Nyaman dalam hal ini terkait faktor fisik dan non-fisik tempat (Rachman dan Kusuma, 2014). Berdasarkan penjelasan yang telah diuraikan, dapat dirumuskan bahwa faktor kebetahan pada kafe dan coffee shop yang terdiri dari faktor fisik dan non-fisik akan sangat berpengaruh pada kunjungan frekuen. Kunjungan frekuen tersebut mengakibatkan perputaran ekonomi dan konsep supply dan demand terjadi. Dikarenakan adanya demand yang tinggi dari masyarakat, akhirnya menyebabkan fenomena terus berkembangnya café society di Bandung, Berangkat dari rumusan tersebut maka dihasilkan simpulan sebagai berikut:

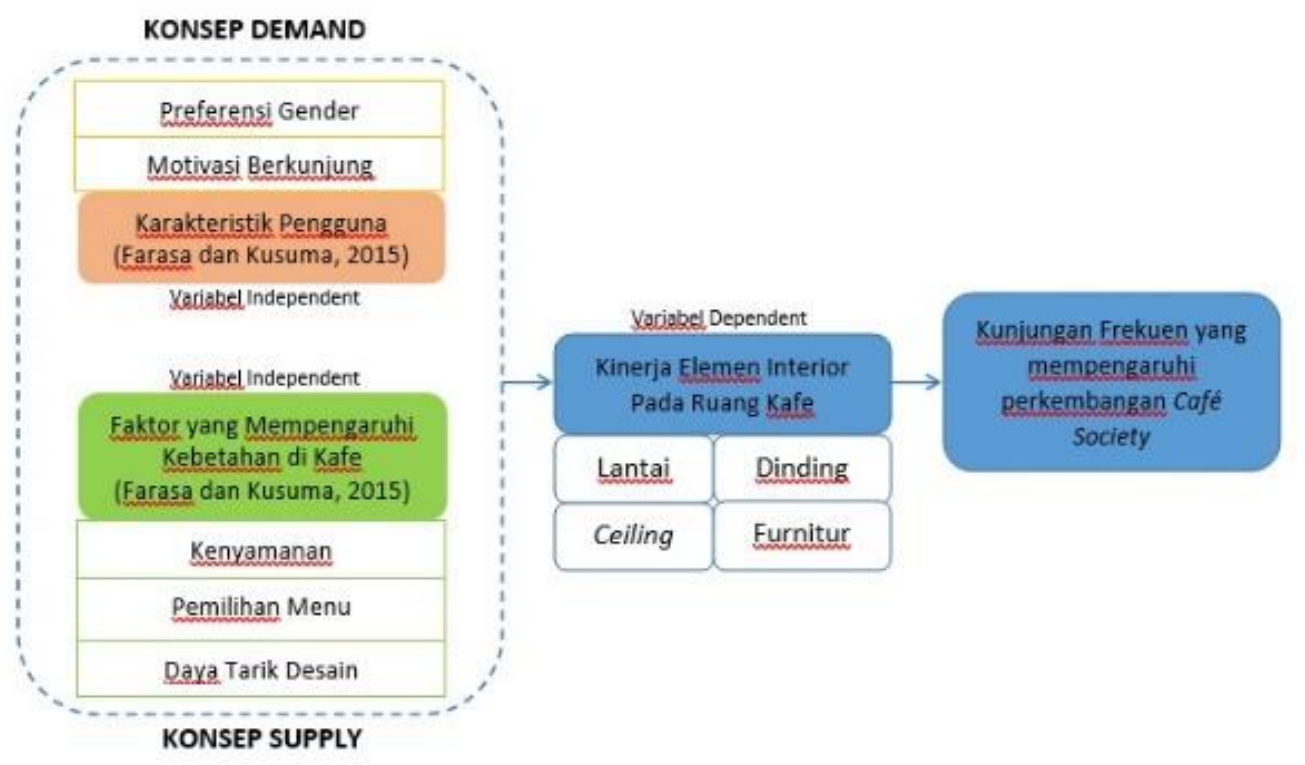

Gambar 1. Diagram Rumusan Kerangka Penelitian Awal Sumber: analisis, 2020

Diagram di atas menjelaskan bahwa penelitian ini berangkat dari adanya konsep demand berupa preferensi gender dan motivasi berkunjung dari konsumen yang kemudian dijawab melalui penawaran konsep kenyamanan, keberagaman menu maupun daya tarik desain oleh pengelola kafe. Kedua hal tersebut kemudian dirumuskan menjadi penilaian terkait kinerja elemen desain interior yang ada pada kafe maupun coffee shop yang dijadikan sebagai objek studi kasus. Data hasil penelitian diharapkan dapat menghasilkan penilaian terkait daya tarik desain interior yang berpengaruh terhadap faktor kebetahan dan menyebabkan kunjungan frekuen terjadi. Melihat banyaknya pengaruh café society pada masyarakat yang diakibatkan salah satunya oleh faktor kebetahan, maka analisis terhadap faktor kebetahan di kafe dan coffee shop tersebut dinilai menjadi 
layak untuk dijadikan bahan penelitian. Penelitian ini bertujuan untuk menilai kinerja dari elemen desain interior yang diterapkan pada kafe dan coffee shop studi kasus. Kinerja yang dimaksud berkaitan dengan faktor desain apa saja yang berpengaruh pada kemungkinan motivasi kunjungan frekuen yang dapat mengakibatkan perkembangan café society terus meningkat.

\section{Tinjauan Pustaka}

\subsection{Fenomena Café Society di Bandung}

Tinamei, 2006 mengartikan fenomena café society sebagai representasi gaya hidup sebuah komunitas atau kelompok urban yang mengutamakan pencarian pengalaman pada ranah hiburan. Saat ini, fenomena tersebut sangat lazim terjadi, salah satunya di Indonesia. Orang-orang banyak menghabiskan waktu dan beraktivitas di kafe. Jika dahulu kafe hanya sebuah tempat untuk menjual makanan kecil dan minuman sekarang berubah menjadi tempat paling diminati masyarakat untuk menghabiskan waktu luang (Farasa, 2015). Desain dari sebuah kafe saat ini juga sangat beragam dan tidak terbatas. Lebih lanjut, Tinamei 2006 menjelaskan bahwa desain tersebut dapat diterjemahkan dengan banyak cara, seperti konsep desain yang ditawarkannya, seluruh suasana yang diciptakannya, konteks tempatnya berdiri, fasilitas hiburan yang dilayaninya, atau bahkan citra gaya hidup yang diwakili melalui penampilan kelas masyarakat yang menempati tempat itu. Di Bandung sendiri menurut data dari Dinas Pariwisata dan Kebudayaan, saat ini terdapat sekitar 795 usaha komersil yang bergerak di bidang kuliner, yang sebagian besar merupakan kafe dan coffee shop. Widiastuti, 2006 menjelaskan bahwa saat ini Bandung telah mengalami transformasi informal. Informalitas ini tidak hanya mengonfigurasi ulang sendiri prospek kemajuan baru, tetapi juga mengubah Bandung sebagai kota dengan ekspresi berbeda. Jika dulu Bandung dikenal sebagai Kota kembang, maka sekarang Bandung diidentifikasikan sebagai tempat makanan dan pakaian berada. Fenomena transformasi informal di Bandung ini tidak hanya mengakibatkan perubahan beberapa daerah sebagai pusat keramaian, melainkan memunculkan berbagai perubahan seperti peralihan fungsi dari kawasan permukiman menjadi kawasan komersial, yang berdampak pada banyaknya perubahan fungsi sebuah bangunan dari fungsi hunian menjadi fungsi lain, sehingga landuse di Bandung saat ini juga turut berubah.

\subsection{Faktor yang Mempengaruhi Kebetahan Pengunjung di Kafe}

Sebagai salah satu bentuk respon psikologis manusia terhadap lingkungannya, kebetahan merupakan hal yang dapat dianggap penting untuk dikaji lebih lanjut sebagai kriteria dalam perancangan pada berbagai macam jenis tempat yang ada pada sebuah lungkungan binaan. Rachman R.A dan Kusuma, H.E. 2014 menjelaskan bahwa istilah kebetahan dapat digunakan sebagai respon terhadap berbagai jenis bangunan atau tempat yang akan dikaji kualitasnya. Jika kebetahan dianggap sebagai satu kondisi dari hasil interaksi yang terjadi antara manusia dengan tempat maka kondisi yang terjadi dapat bersifat positif maupun negatif. Apa yang dirasakan dalam kebetahan dapat digambarkan dari bagaimana manusia memperlakukan tempat itu sendiri. Jika dihubungkan dengan konteks arsitektur, maka kebetahan dapat berupa respon dari interaksi manusia dengan ruang arsitektural. Rancangan ruang yang berkualitas sewajarnya dapat menghasilkan tingkat kebetahan yang positif

Kebetahan diartikan sebagai perbuatan atau pencerminan dari kondisi psikologis penghuni, karena sudah merasa senang di suatu tempat yang dicerminkan melalui lama tinggal, rencana penghunian, dan kepuasan penghunian. Sehingga dapat ditarik kesimpulan bahwa kebetahan seseorang berada di sebuah kafe merupakan suatu kondisi psikologis seseorang karena merasa nyaman, senang, dan puas dengan segala suasana dan fasilitas yang ada sehingga seseorang tanpa sadar telah menghabiskan waktunya lama di kafe tersebut (Farasa, N dan Kusuma, H.E, 2015). Adapun faktor penyebab betah diantaranya adalah faktor kenyamanan, pemilihan menu, dan daya tarik desain. Hay, 1998 dalam Scanell, L dan R. Gifford, 2010 menjelaskan bahwa dalam ilmu arsitektur dan desain interior, fenomena keterikatan antara manusia dan lingkungan fisik masuk ke dalam pembahasan keterikatan tempat (place attachment). Dalam pembahasan yang lebih besar beberapa peneliti mengaitkan keterikatan tempat sebagai sub-sektor dari teori Sense of Place meliputi di dalamnya bahasan tentang Place Identity (identitas tempat).

\subsection{Kawasan L.R.E Martadinata, Bandung}

Kawasan L.R.E Martadinata atau dikenal juga sebagai Jalan Riau merupakan sebuah jalan yang terdapat di Kelurahan Citarum, Kecamatan Bandung Wetan. Kawasan ini terdiri jalan utama/ layer 1, yaitu area sepanjang Jalan Riau serta layer 2, yaitu jalan sekitarnya yang terdiri dari beberapa jalan seperti Jalan Progo, 
Jalan Cimanuk. Peruntukan lahan di Kawasan Riau secara aturan landuse dari pemerintah di tahun 2015 berbeda-beda. Koridor L.R.E Martadinata difungsikan untuk kegiatan komersial, sedangkan jalan pada layer 2 masih tercatat sebagai kawasan permukiman. Penggiat Sejarah Kota Bandung, Iwan Hermawan (41), menjelaskan bahwa pada jaman dulu, kawasan ini dibangun menjadi sebuah perumahan elit untuk orang-orang Eropa. "Berawal dari pembangunan itu, Jalan Riau menjadi kawasan kegiatan bangsa eropa atau disebut Europese Zakenwijk," Ketika pergantian kekuasaan, dari Pemerintah Kolonial Belanda ke Pemerintah Jepang, terjadi beberapa perubahan pula pada daerah ini. Setelah kemerdekaan, Pemerintah Indonesia melakukan langkah nasionalisasi terhadap berbagai aset semisal perumahan, bank, perusahaan, hotel, dan lain-lain. Banyak rumah yang kemudian diambil alih menjadi milik Pemerintah Indonesia dan seiring berjalannya waktu, lahan permukiman yang berada dekat di pusat pemerintahan mulai dalihfungsikan masyarakat menjadi ladang bisnis bangunan komersil hingga saat ini.

\section{Metode Penelitian}

Pengambilan data lapangan dilakukan dengan cara observasi lapangan. Observasi lapangan menghasilkan data berupa dokumentasi kejadian-kejadian yang dianggap terkait dengan tujuan penelitian berupa foto dan video, melihat pergerakan pengunjung dan menentukan kegiatan apa saja yang dilakukan oleh mereka sebagai objek penelitian. Pengambilan data kuesioner dalam penelitian ini dilakukan dengan cara online questionnaire atau pengambilan secara online. Kuesioner diperuntukkan bagi pengunjung, yaitu siapapun yang pernah mengunjungi lokasi kafe dan coffee shop studi kasus. Pengambilan sampel sendiri menggunakan metode non-random/ probability sampel atau sudah diarahkan dari awal penelitian menggunakan tipe accidental (Kumar, 2005), di mana sampel yang dipilih adalah siapapun yang ditemukan peneliti dan memenuhi syarat sebagai orang yang pernah berkunjung ke kafe dan coffee shop studi kasus.

Untuk Syarat dari sampel pengunjung sendiri adalah kuesioner minimal harus diisi oleh klasifikasi remaja (11-19 tahun) hingga dewasa (20-60 tahun) yang pernah berkunjung ke Dakken Restaurant dan Jardin Café. Adapun alasan pemilihan dua tempat di atas sebagai studi kasus dikarenakan kedua kafe tersebut memiliki indikasi konsep desain yang sangat berbeda, namun sama-sama menarik dan digemari. Selain itu, adanya perbedaan selama 18 tahun dalam masa operasi juga menjadi pertimbangan jika dihubungkan dengan konteks tipologi.Data sampling yang didapat adalah hasil pengisian kuesioner online dari 31 responden, dengan detail 2 orang kategori remaja (19 tahun), dan 28 orang kategori dewasa (rentang umur 20-47 tahun). Sampel penulis anggap telah memenuhi syarat karena telah terdapat wakil dari setiap kategori populasi yang bersumber pada aturan WHO.

Metode analisis data yang digunakan adalah analisis campuran atau mixed-methods, metode ini dipilih karena memungkinkan untuk dilakukan pengumpulan serta analisis data secara kualitatif dan kuantitatif dalam sebuah studi secara sekaligus (Creswell, 2003). Tujuan dipilihnya metode penelitian ini diharapkan dapat menghasilkan hasil analisis yang detail, karena data yang digunakan lebih bervariatif. Prosedur analisis data yang dilakukan adalah adanya transformasi data, yaitu merubah data kualitatif yang didapat dari kuesioner open-ended atau bersifat terbuka serta data kualitatif studi literatur menjadi kode untuk dianalisis secara kuantitatif dengan pertanyaan lainnya yang sudah dibuat kuantitatif dari awal (kualitatif menjadi kuantitatif). Kemudian, data kuantitatif tersebut dianalisis secara analisis kuantitatif dan dibuat interpretasinya dengan menambahkan teori dan data lainnya (foto, diagram dll.) yang bersifat kualitatif (kuantitatif menjadi kualitatif).

\section{Hasil dan Pembahasan}

Di dalam pembahasan penelitian ini, konteks tipologi kafe yang dimaksud adalah pemilihan kafe yang didasarkan pada kemungkinan pengelompokan objek arsitektural karena mempunyai kesamaan sifat (Anthony, Vidler, 1976 dalam Ardina, 2017) yaitu fungsi bangunan dan ruangnya. Konteks tripologi menjadi dasar pemilihan Dakken Restaurant dan Jardin Café sebagai objek studi kasus. Menilik pada tujuan penelitian, yaitu untuk mengetahui apakah desain interior berpengaruh terhadap kebetahan di kafe dan coffee shop, maka dua tempat dengan tipologi fungsi yang sama namun memiliki perbedaan penggayaan, dan tahun berdiri dipilih agar didapat perbandingan yang jelas sebagai indikator dari variable-variabel penelitian untuk kemudian dibahas secara rinci dan diinterpretasikan secara lebih lanjut terkait faktor-faktor kebetahan pengunjung yang dari aspek kinerja elemen desain interior. 


\subsection{Analisis Faktor Kebetahan Pada Dakken Restaurant}

\subsubsection{Deskripsi Dakken Restaurant}

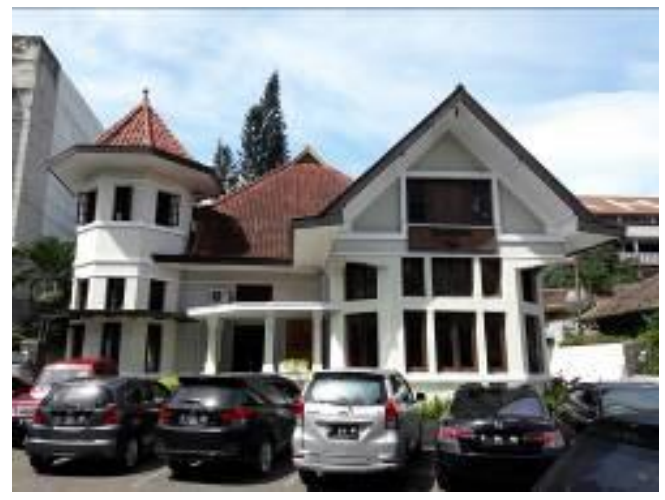

Gambar2. Facade Dakken Restaurant

Dakken Restaurant merupakan sebuah kafe yang telah berdiri sejak tahun 2000. Bertempat di bangunan bergaya art deco yang disebut-sebut telah dibangun pada tahun 1930, hingga saat ini Dakken tetap eksis walaupun di Kawasan Riau bermunculan kafe-kafe baru dengan konsep yang dianggap lebih kekinian. Dakken memiliki kapasitas hingga sekitar 150 orang. Bangunan terdiri dari bangunan utama (area heritage), area outdoor berupa gazebo privat dan komunal serta ruang tambahan (annex) di area belakang tapak. Visi dari Dakken adalah menghadirkan pengalaman unik saat makan dengan cara membawa pengunjung seakan-akan flashback ke masa lampau. Dakken menyebut konsep penggayaan yang mereka usung sebagai dekorasi vintage. Kelebihan dan ciri khas Dakken adalah organisasi ruang berbentuk kluster yang terbentuk dari fungsi kamar dan ruang privat pada penggunaan eksisting sebagai rumah tinggal sebelum berubah fungsi seperti saat ini. Tipologi kluster tersebut kemudian menjadi kelebihan dan ciri khas dari Dakken. Kegiatan seperti rapat, pertemuan kecil, dan arisan yang memerlukan ruang privat dapat diakomodasi dengan baik di sini. Dari segi penggayaan, konsep vintage dan nuansa art deco (colonial) yang berasal dari arsitektur bangunan memberikan kesan cozy. Penghawaan dan pencahayaan alami dapat masuk dengan baik ke bangunan akibat adanya alur sirkulasi dari implementasi keberadaan pintu, jendela, dan kondisi langit-langit yang tinggi dan juga area garden yang besar. Selain itu, pemilihan warna dengan tone neutrals dan palette earth tone memberikan kesan tenang dan hangat pada pengguna. Implementasi palet warna tersebut kebanyakan di dapat dari penerapan elemen material dan finishingnya yang didominasi oleh material alam (kayu) dan sedikit sentuhan besi tempa dan kaca. Selain itu, keberadaan area hijau dan tanaman di sekitar kafe pun menjadi salah satu daya tarik utama saat berkunjung ke Dakken.

\subsubsection{Analisis Faktor Attraction pada Dakken Restaurant}

Faktor attraction dapat diartikan sebagai kemampuan tempat menarik perhatian orang untuk datang (Siahaan 2010). Faktor attraction memiliki dua kategori penilaian yaitu kategori tempat (setting) dan kategori peristiwa (Inskeep, 1991; Lynch, 1980; Banerjee. 2001; Dwiananto A, 2003 dalam Haristianti, Kurniati, Syari, 2015). Dalam penelitian ini, kategori tempat dijabarkan dalam dua pembahasan yaitu, daya tarik desain dan kenyamanan. Sedangkan kategori peristiwa dijabarkan dalam pembahasan faktor kegiatan:

\section{Faktor Daya Tarik Desain}

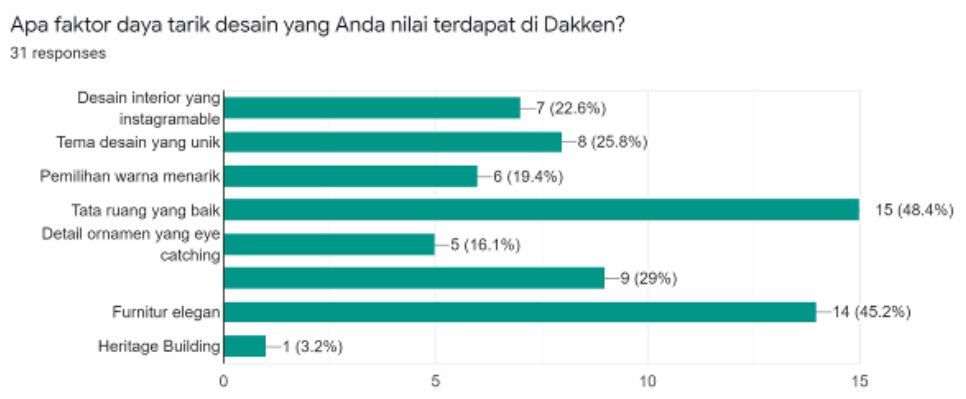

Gambar 3 Faktor daya tarik desain di Dakken

Dari hasil analisis distribusi frekuensi yang didapat dengan cara memberikan pertanyaan berupa checkbox, dapat dijelaskan bahwa menurut responden daya tarik desain utama yang terdapat di Dakken di antaranya 
adalah: tata ruang yang baik (15 responden), furnitur yang elegan (14 responden), pengolahan material yang maksimal (9 responden), dan tema desain yang unik.

2. Faktor Kenyamanan

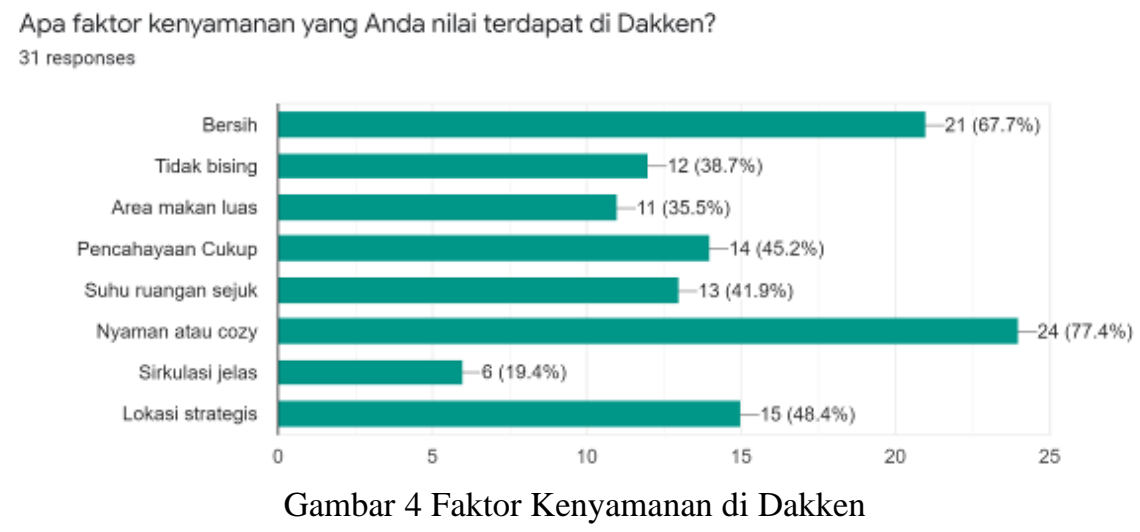

Untuk faktor kenyamanan, didapatkan hasil berupa poin suasana cozy (24 responden), kebersihan (21 responden), Lokasi strategis (15 responden), serta Pencahayaan yang cukup (14 responden) yang menjadi factor-faktor utama pembentuk kenyamanan pengunjung.

3. Faktor Kegiatan

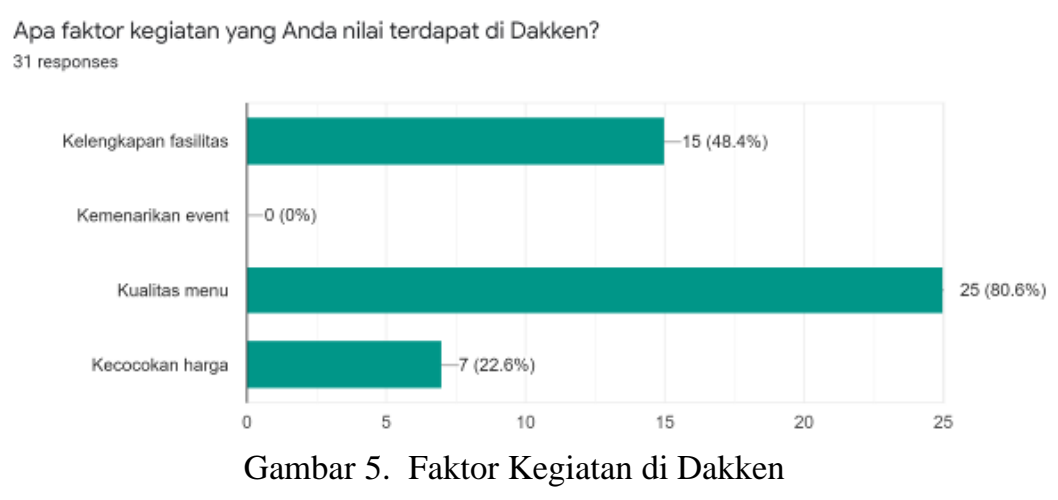

Pada faktor kegiatan, kualitas menu (25 responden) dan kelengkapan fasilitas (15 responden) menjadi poin kunci pembentuk daya Tarik kegiatan di Dakken. Hasil analisis distribusi frekuensi di atas kemudian dikorelasikan dengan area favorit dan rata-rata durasi berkunjung di bawah ini:
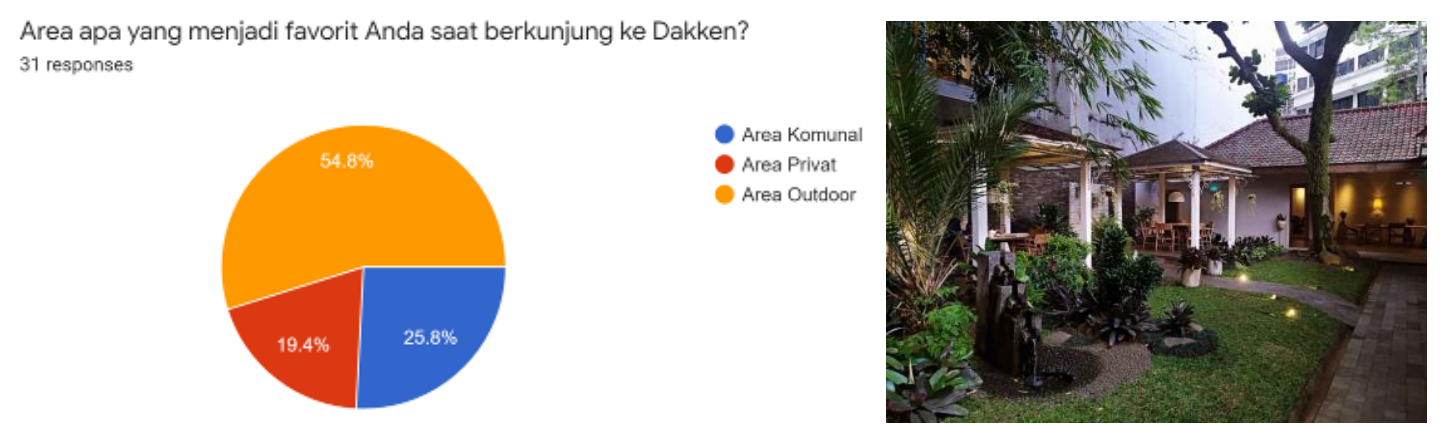

Gambar 6 Area atau spot favorit di Dakken

Dengan durasi berkunjung rata-rata selama 2-3 jam, area favorit yang dipilih oleh pengunjung adalah area outdoor. Area outdoor di Dakken sendiri terbagi menjadi beberapa area, diantaranya adalah area beranda, gazebo privat dan gazebo publik. Area ini berada di halaman belakang dari Dakken Restaurant berupa taman/ ruang terbuka. Area ini memiliki atmosfer yang sejuk karena dikelilingi pohon yang rindang, elemen air namun juga masih dapat terkendali dari terik matahri karena dining areanya tetap memiliki atap. Maka, dari hasil 
penjelasan setiap bagian di atas, dapat disimpulkan bahwa daya tarik utama penyebab kebetahan dan kunjungan ulang yang dimiliki oleh Dakken Restaurant yang berhubungan dengan kinerja elemen desain interior adalah: tata ruang yang baik, furniture yang elegan, pengolahan material yang maksimal, tema desain yang unik. suasana cozy, pencahayaan yang cukup dan kelengkapan fasilitas. Selain itu, pengunjung memilih area outdoor sebagai representasi terbaik dari penerapan faktor attraction di Dakken Restaurant.

\subsubsection{Analisis Kinerja Elemen Interior di Dakken Restaurant}

1. Kinerja Pengolahan Elemen dan Material Lantai

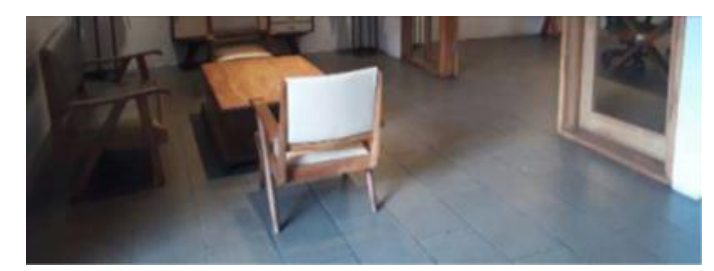

Gambar 7. Pengolahan elemen lantai pada area privat

Material teracota, tegel, keramik tile dan paving block yang dipilih sebagai elemen lantai dinilai cocok secara estetika saat diterapkan dengan penggayaan vintage yang Dakken usung, baik dari segi warna, kesesuaian dengan tema, maupun efek yang ditimbulkan pada atmosfir ruang. Secara garis besar, peran implementasi material lantai pada faktor kebetahan di Dakken dinilai berpengaruh.

\section{Kinerja Pengolahan Elemen dan Material Dinding}

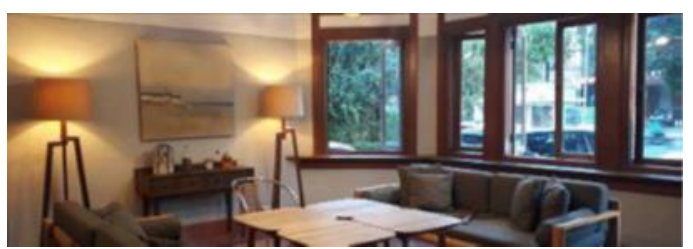

Gambar 8. Pengolahan elemen dinding pada area privat di Dakken

Pemilihan jenis material serta pengolahan nya terhadap elemen dinding dinilai baik. Dalam implementasinya, Dakken memilih material dinding dengan finishing cat tembok untuk area outdoor, dan finishing wallpaper serta cat kayu warna natural tipe transparan untuk jendela dan pintunya. Selain itu, dinding juga diberi dekorasi berupa artwork lukisan dan elemen estetik yang didominasi material kaca dan besi serta lampu dinding. Pada beberapa sisi, terdapat pula mural yang memiliki warna kontras dengan finishing wallpaper di area dinding sekelilingnya. Komposisi material-material di atas sebagai elemen dinding dinilai cocok secara estetika saat diterapkan dengan penggayaan vintage yang Dakken usung, baik dari segi warna, kesesuaian dengan tema, maupun efek yang ditimbulkan pada atmosfir ruang. Secara garis besar, peran implementasi material dinding pada faktor kebetahan di Dakken dinilai berpengaruh.

\section{Kinerja Pengolahan Elemen dan Material Langit-langit}

Pemilihan jenis material serta pengolahan terhadap elemen langit-langit dinilai baik. Dalam implementasinya, Dakken memilih material langit-langit ekspose pada area bangunan utama (heritage) yang difinishing cat, dan gazebo semi outdoor dengan finishing cat kayu pada elemen kuda-kuda. Namun, pada area annex (tambahan).

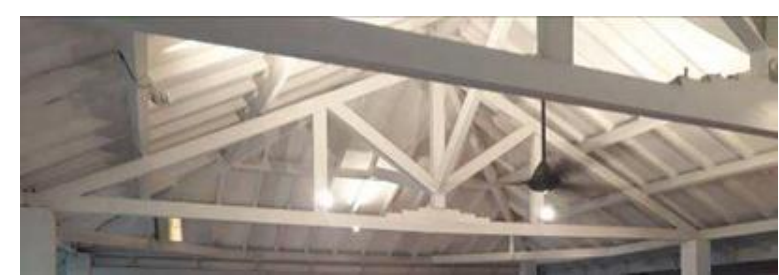

Gambar 9. Pengolahan elemen langit-langit pada area semi outdoor (gazebo) komunal

Tipe langit-langit yang dipilih adalah drop ceiling yang diberi finishing gypsum board dan cat. Secara umum, jenis lampu yang digunakan pada system pencahayaan general adalah lampu bohlam LED dengan 
warna cahaya warm. Namun pada beberapa ruangan, diberi tambahan dekorasi berupa chandelier sebagai point of interest di bagian tengah ruang yang desainnya sesuai dengan konsep penggayaan yang Dakken usung. Maka dari itu, disimpulkan bahwa, peran implementasi material langit-langit pada faktor kebetahan di Dakken dinilai berpengaruh. Terutama karena membantu terbentuknya atmosfir ruang dari pencahayaan general maupun aksen yang berasal dari lampu di langit-langit.

\section{Kinerja Pengolahan Elemen Furnitur}
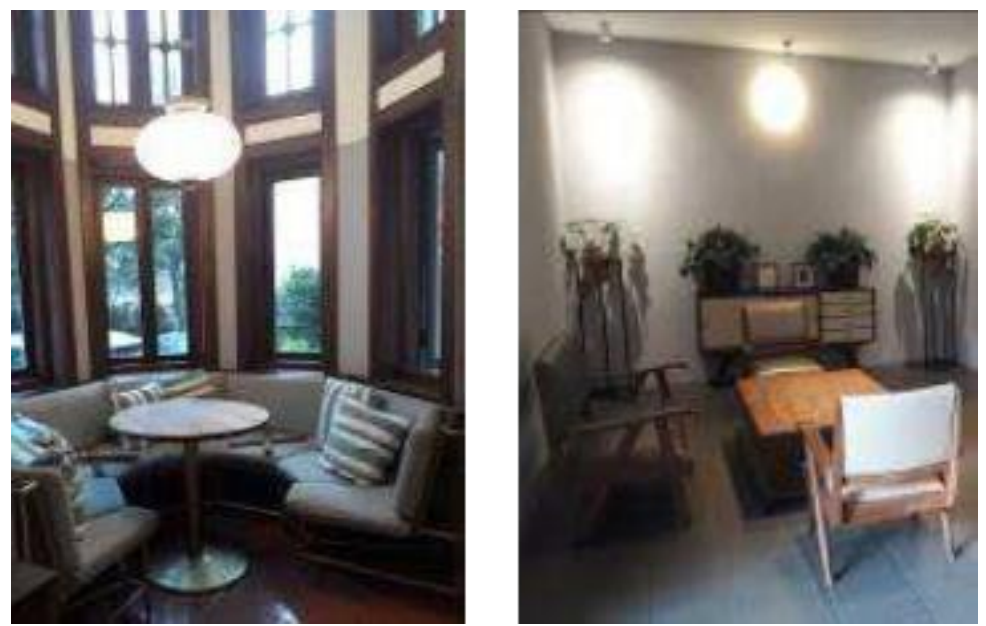

Gambar 10-11. Implementasi pengolahan desain furnitur mobile pada beberapa area di Dakken

Dalam implementasinya, Secara umum Dakken memilih material kayu asli dengan finishing natural transparan untuk dipakai dalam hampir seluruh desain furnitur pada tiap-tiap ruang. Adapun jenis furnitur yang berada di Dakken kebanyakan bersifat build in dan free standing. Tone warna yang dihasilkan dari elemen kayu alami ini pada akhirnya menghasilkan kesan homy. Maka dari itu, disimpulkan bahwa, peran implementasi furnitur merupakan salah satu hal yang vital pada faktor kebetahan di Dakken. Bentukan dan materialnya dinilai berpengaruh. Terutama karena membantu terbentuknya atmosfir ruang yang berasal dari tone warna dan sifat material kayu yang dominan pada furnitur.

5. Kinerja Pengolahan Ornamen

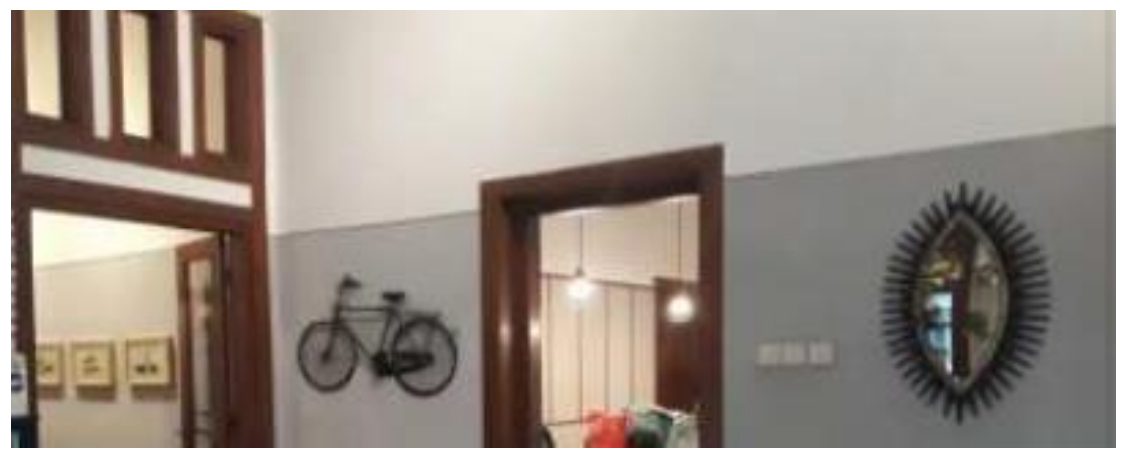

Gambar 12. Implementasi ornamen pada beberapa sudut ruang di Dakken

Pengolahan ornamen yang terdapat di Dakken dinilai baik. Dalam implementasinya, Secara umum Dakken memiliki bentukan ornamen yang kuat hubungannya dengan penggayaan art deco dari konsep arsitektur bangunan. Kebanyakan dari ornamen tersebut terdapat di bentukan kusen, dan lubang angin. Adapun selain itu berasal dari elemen estetik yang ada di dinding kafe. Material yang digunakan selaras dengan ciri khas penggayaan art deco yaitu besi, kuningan dan kaca-kaca. Ornamen-ornamen ini menghasilkan keindahan baru dalam ruang. Maka dari itu, disimpulkan bahwa, peran implementasi ornamen dinilai berpengaruh terhadap faktor kebetahan saat mengunjungi Dakken. Terutama karena menambah focal point pada ruang, dan menghasilkan naiknya aspek estetika dalam ruang. 


\subsection{Analisis Faktor Kebetahan Pengunjung Pada Jardin Cafe}

\subsubsection{Deskripsi Jardin Cafe}
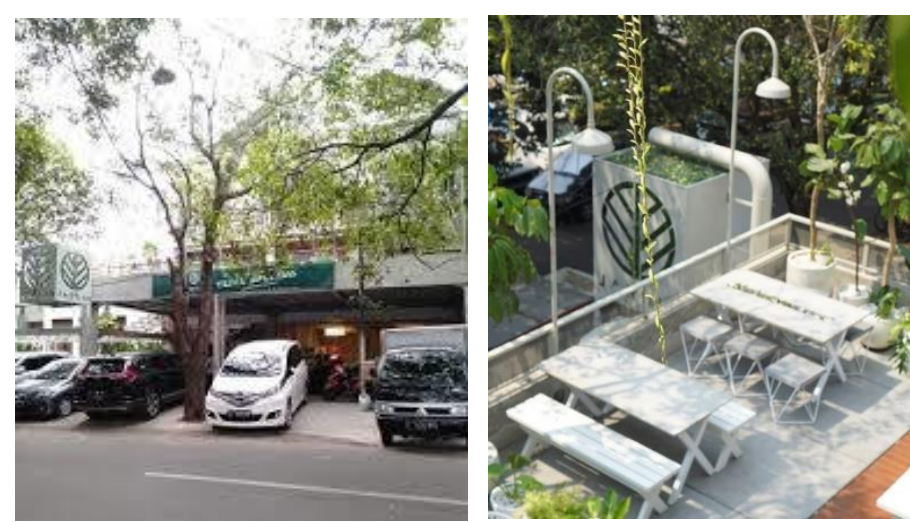

Gambar13. Facade Jardin Cafe (Sumber: Instagram Jardin cafe)

Jardin Cafe merupakan sebuah kafe yang mulai beroperasi pada awal tahun 2018. Berdiri di atas bangunan tiga lantai, konsep yang diusung kafe ini menurut desainer interiornya adalah conservatory. Filosofi dari konsep desain Jardin yaitu ingin menciptakan ruang hijau yang dapat menjadi penyambung bagi manusia dan unsur-unsur vegetasi hidup bersama secara harmony. Implementasi dari konsep ini dituangkan dalam sebuah bentukan ruang yang didominasi ruangan terbuka dan semi terbuka serta dipenuhi dengan vegetasi yang membentuk semacam lush garden, yaitu bentukan taman yang diisi oleh tanaman rimbun. Konsep ini seringkali dikaitkan dengan tema tropical. Jardin menjadi tempat yang sangat diminati pada awal mula pembukaannya. Hal ini dikarenakan desain dari Jardin dinilai instagrammable, yaitu fenomena dari adanya kegandrungan untuk mengunggah swafoto dan menguploadnya ke laman social media. Instagramable di sini diartikan sebagai persepsi pengunjung yang beranggapan bahwa desain dari Jardin memiliki daya tarik sehingga patut dijadikan sebagai tempat berfoto dan menarik banyak orang.

Secara konsep, conservatory diimplementasikan dengan cara menganalogikan bangunan kafe sebagai sebuah green house yang diisi oleh berbagai macam tanaman. Perawatan untuk tanamannya sendiri diatur dengan sistem penyiraman otomatis. Untuk materialnya, arsitektur Jardin didominasi dengan material beton ekspose dan baja tanpa finishing. Kedua material ini sedang marak digunakan dan sangat digandrungi. Kesan brutalism dari kedua material tersebut dianggap dapat merepresentasikan kesan alami atau natural yang menjadi konsep besar. Adapun tujuan dari penerapan konsep desain ini adalah Jardin berharap dapat menjadi sebuah tempat seperti utopia, yang dapat dijadikan tempat istirahat dan bersantai dengan suasana rimbun bagi pengunjung setelah melakukan kegiatannya sehari-hari, tanpa harus jauh-jauh berlibur ke daerah Bandung atas yang terkenal sejuk, cukup tetap dating ke lokasi strategis (di tengah kota), yaitu di sekitaran Jalan Riau.

\subsubsection{Analisis Faktor Attraction pada Jardin Kafe}

Sama seperti pada analisis di Dakken Restaurant, dalam pembahasan ini, kategori tempat dijabarkan dalam dua pembahasan yaitu, daya tarik desain dan kenyamanan. Sedangkan kategori peristiwa dijabarkan dalam pembahasan factor kegiatan. Untuk lebih jelasnya dijabarkan dalam diagram di bawah ini:

1. Faktor Daya Tarik Desain

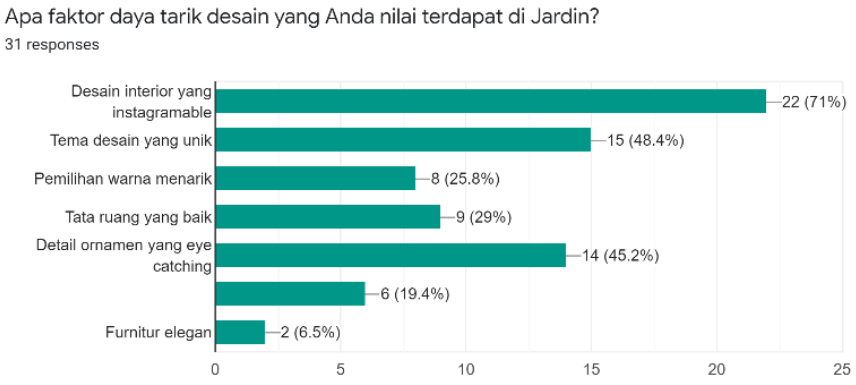

Gambar 14 Faktor daya tarik desain di Jardin 
Dari hasil analisis distribusi frekuensi yang didapat dengan cara memberikan pertanyaan berupa checkbox multiple answer, dapat dijelaskan bahwa menurut responden daya tarik desain utama yang terdapat di Jardin diantaranya adalah: Desain interior yang instagramable (22 responden), Tema desain yang unik (15 responden), serta detail ornament yang eye-catching (14 responden).

2. Faktor Kenyamanan

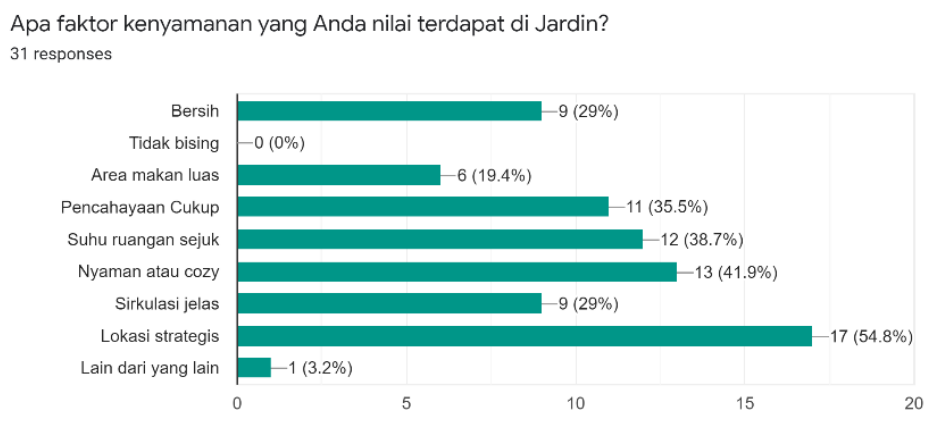

Gambar 15 Faktor kenyamanan di Jardin

Untuk faktor kenyamanan, didapatkan hasil berupa poin lokasi strategis (17 responden), nyaman atau suasana cozy (13 responden), suhu ruangan sejuk (12 responden), serta pencahayaan yang cukup (11 responden) yang menjadi faktor-faktor utama pembentuk kenyamanan pengunjung.

\section{Faktor Kegiatan}

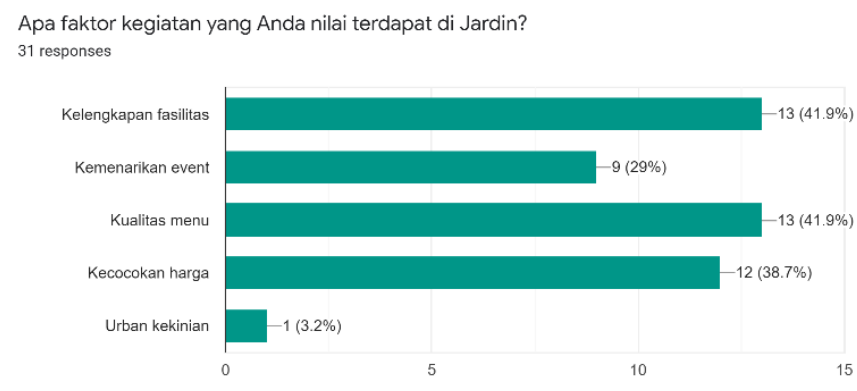

Gambar 16 Faktor kegiatan di Jardin

Pada faktor kegiatan, kualitas menu dan kelengkapan fasilitas (masing-masing 13 responden) serta kecocokan harga (12 responden) menjadi poin kunci pembentuk daya Tarik kegiatan di Jardin. Hasil analisis distribusi frekuensi di atas kemudian dikorelasikan dengan area favorit dan rata-rata durasi berkunjung di bawah ini:
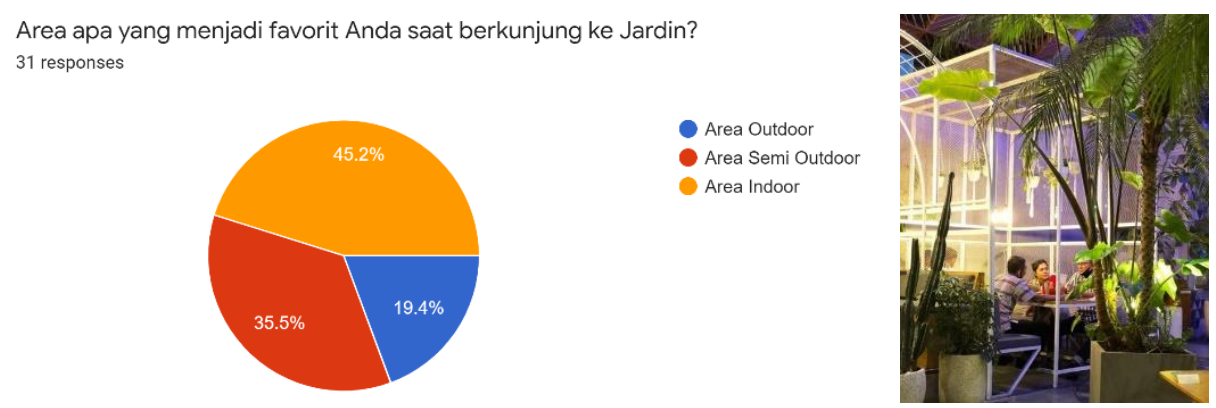

Gambar 17 Area favorit saat berkunjung ke Jardin

Dengan durasi berkunjung rata-rata selama 2-3 jam (51.6\% responden), area favorit yang dipilih oleh pengunjung adalah area indoor. Area indoor di Jardin terdiri dari beberapa bagian. Namun, konsepnya sama yaitu merupakan atrium beratap namun dengan bukaan besar berupa gawangan dan dipenuhi pohon yang rindang dari implementasi keberadaan lush garden yang rimbun. Maka, dari hasil penjelasan setiap bagian di atas, dapat disimpulkan bahwa daya tarik utama penyebab kebetahan dan kunjungan ulang yang dimiliki oleh 
Jardin Café yang berhubungan dengan kinerja elemen desain interior adalah: instagramable, Tema desain yang unik, detail ornament yang eye-catching, suasana cozy, pencahayaan yang cukup, suhu yang sejuk, serta kelengkapan fasilitas. Selain itu, pengunjung memilih area indoor sebagai representasi terbaik dari penerapan faktor atraksi di Jardin Kafe.

\subsubsection{Analisis Kinerja Elemen Interior di Jardin Cafe}

1. Kinerja Pengolahan Elemen dan Material Lantai

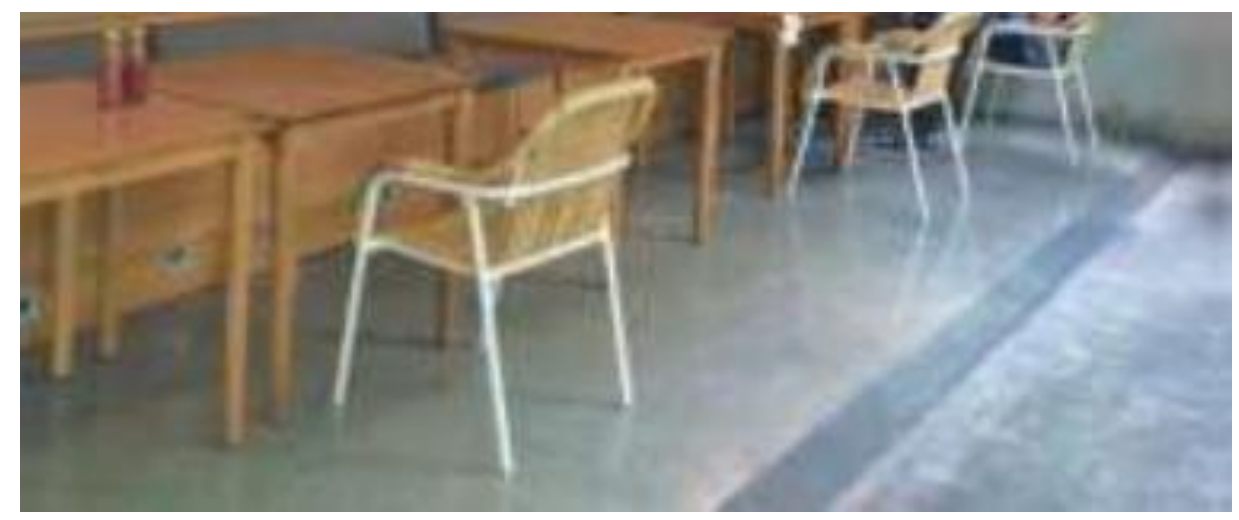

Gambar 18. Pengolahan elemen lantai pada area outdoor, semi indoor dan indoor di Jardin

Pemilihan jenis material serta pengolahan nya kepada elemen lantai dinilai sudah cukup baik. Material kayu, concreate dan lantai keramik yang dipilih sebagai elemen lantai dinilai cocok secara estetika saat diterapkan dengan penggayaan conservatory yang Dakken usung, baik dari segi warna, kesesuaian dengan tema, maupun efek yang ditimbulkan pada atmosfir ruang. Secara garis besar, peran implementasi material lantai pada faktor kebetahan di Jardin dinilai berpengaruh.

2. Kinerja Pengolahan Elemen dan Material Dinding

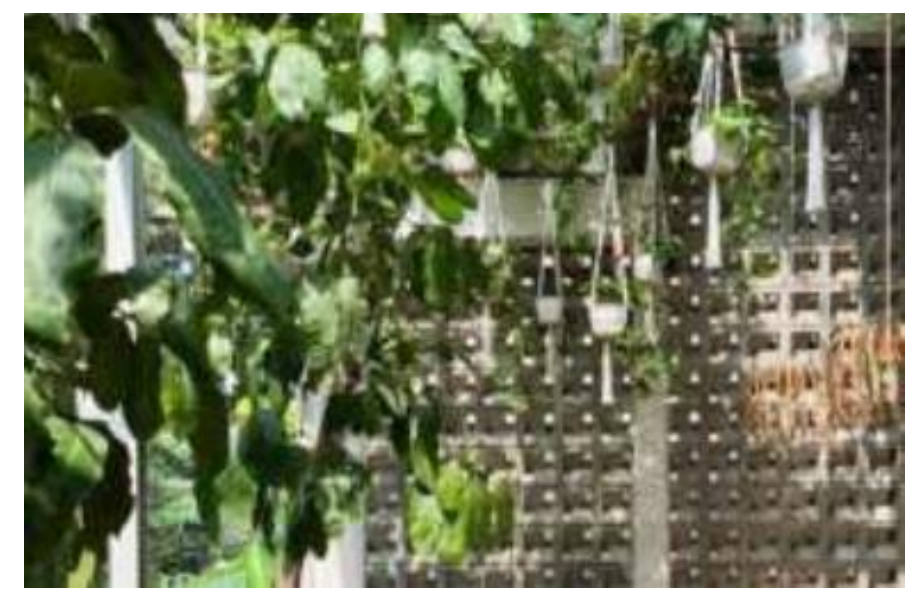

Gambar 19. Pengolahan elemen dinding pada area outdoor di Jardin

Pemilihan jenis material serta pengolahan nya terhadap elemen dinding dinilai sangat baik. Dalam implementasinya, Jardin memilih material dinding dengan concrete ekspose pada keseluruhan bangunan, namun pada beberapa sisi ditambahkan kombinasi finishing material jalusi concreate, railing baja transparan tanpa finishing, elemen estetik berupa mural, serta tumbuh-tumbuhan. Agak sulit untuk mengkategorisasi area di Jardin secara spesifik karena sebenarnya hampir dari keseluruhan area berbentuk semi outdoor. Namun, intinya komposisi material-material di atas sebagai elemen dinding dinilai cocok secara estetika saat diterapkan dengan penggayaan conservatory yang Jardin usung, baik dari segi warna, kesesuaian dengan tema, maupun efek yang ditimbulkan pada atmosfir ruang. Secara garis besar, peran implementasi material dinding pada faktor kebetahan di Jardin dinilai berpengaruh. 
3. Kinerja Pengolahan Elemen dan Material Langit-langit
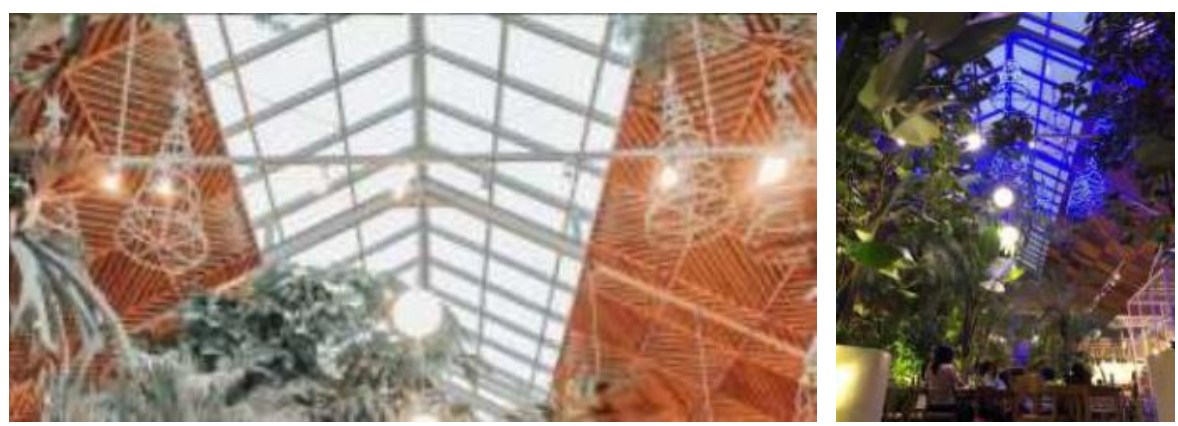

Gambar 20. Pengolahan elemen ceiling pada lantai dua di Jardin saat siang dan malam

Pemilihan jenis material serta pengolahan terhadap elemen langit-langit dinilai baik. Dalam implementasinya, Jardin memilih material langit-langit kayu ekspose (true ceiling) dengan variasi skylight pada desain langit-langitnya. Secara umum, jenis lampu yang digunakan pada system pencahayaan general adalah lampu bohlam LED dengan warna cahaya yang unik, yaitu warna cahaya warm sebagai pencahayaan general dan aksen warna neon (ungu), mengingatkan kita pada hutan di dalam film avatar. Di beberapa sisi ruangan juga ditambahkan pendant lamp berbentuk lampu taman bulat. Selain itu, yang menjadi keunikan adalah dekorasi musiman yang menyesuaikan dengan kegiatan atau event yang sedang terjadi, seperti contoh tema lebaran, natal, dan valentine. Point of interest lainnya adalah keberadaan tanaman gantung pada beberapa area langit-langit. Hal ini memperkuat konsep conservatory/ green house yang Jardin usung dan mengakibatkan bertambahnya kesan rimbun. Maka dari itu, disimpulkan bahwa, peran implementasi material dan desain langit-langit pada faktor kebetahan di Jardin dinilai berpengaruh. Terutama karena membantu terbentuknya atmosfir ruang dan suasana conservatory yang ingin disampaikan.

\section{Kinerja Pengolahan Elemen Furnitur}
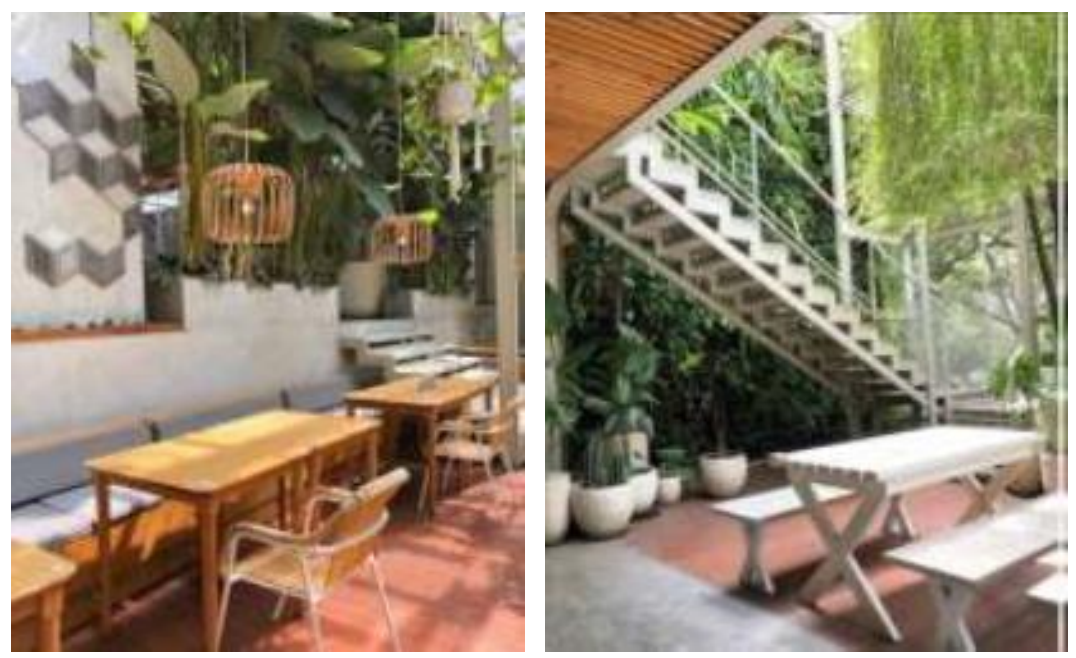

Gambar 21. Implementasi pengolahan desain furnitur pada beberapa area di Jardin

Jenis furniture dan material yang terdapat di Jardin dinilai sangat baik. Dalam implementasinya, Secara umum Jardin memilih material kayu dengan finishing natural transparan untuk dipakai dalam hampir seluruh desain furnitur pada tiap-tiap area. Adapun jenis furnitur yang berada di Jardin kebanyakan bersifat free standing dengan desain minimalis sedikit mengarah ke penggayaan Scandinavian. Tone warna yang dihasilkan dari elemen kayu alami ini menghasilkan kesan natural, perasaan saat duduk di sana terasa seperti saat kita duduk di bangku taman. Maka dari itu, disimpulkan bahwa, peran implementasi furnitur merupakan salah satu hal yang penting pada faktor kebetahan di Jardin. Bentukan dan materialnya dinilai berpengaruh. Terutama karena membantu terbentuknya atmosfir ruang yang berasal dari tone warna dan pendekatan desain dari gubahan furniture yang ada. 
5. Kinerja Pengolahan Ornamen

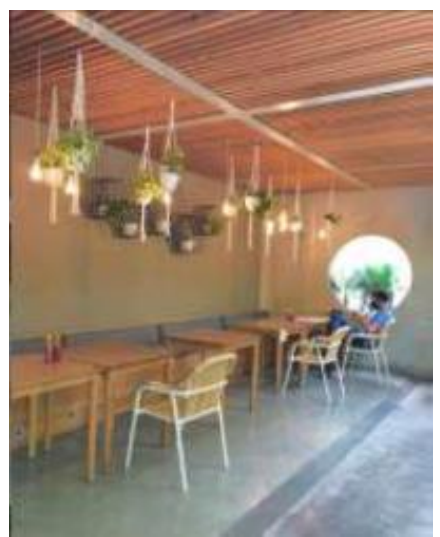

Gambar 22. Implementasi ornamen pada beberapa sudut ruang di Jardin

Pengolahan ornament yang terdapat di Jardin dinilai baik dari segi implementasinya, Secara umum Jardin memiliki bentukan ornament yang kuat hubungannya dengan konsep conservatory/ green house yang mereka usung. Kebanyakan dari ornamen tersebut terdapat di bentukan jalusi, serta implementasi dari keberadaan tumbuhan. Adapun selain itu berasal dari elemen estetik yang ada di dinding kafe dan jug a bentukan pot tanaman. Materialnya sendiri banyak menggunakan material ekspose yang menghasilkan efek raw, natural dan transparan. Ornamen-ornamen ini menghasilkan keindahan baru dalam ruang. Maka dari itu, disimpulkan bahwa, peran implementasi ornamen dinilai berpengaruh terhadap faktor kebetahan saat berkunjung ke Jardin

\subsection{Perbedaan Motivasi Gender dalam Preferensi Pemilihan Kafe}

Tujuan kedua dari penelitian ini adalah untuk mengetahui apa yang menjadikan motivasi utama dalam berkunjung ke Kafe untuk perempuan dan laki-laki. Apakah ada perbedaan dalam memilih kafe yang akan dikunjungi atau tidak. Terdapat 6 orang $(19,4 \%)$ responden laki-laki dan 25 orang $(80,6 \%)$ responden perempuan dalam proses pengisian kuesioner. Hasil dari kuesioner yang menunjukan motivasi berkunjung ke kafe dari gender dapat dilihat pada gambar 23.

\section{Apa faktor terpenting yang membuat Anda mengunjungi sebuah Kafe?}

31 responses

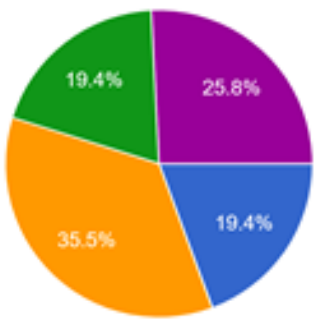

Sosialisasi

Hobi

Kenyamanan

- Menu

- Daya Tarik Desain

Gambar 23. Implementasi ornamen pada beberapa sudut ruang di Jardin

Empat responden pria memilih daya tarik desain sebagai factor utama pemilihan kafe (50\% dari total 8 responden). Sedangkan perempuan kebanyakan memilih faktor kenyamanan (11 orang/35\% dari keseluruhan responden). Adapun faktor terpenting yang menjadi alas an pengunjung untuk berkunjung pada dua studi kasus adalah kenyamanan, daya tarik menu, menu makanan, dan sosialisasi.

\section{Kesimpulan}

Dari hasil penelitian, dapat disimpulkan bahwa kinerja elemen desain interior sangat berpengaruh terhadap faktor kebetahan pengunjung di coffee shop dan kafe. Hal ini selaras dengan beberapa pendekatan yang terdapat pada keilmuan Desain Interior yang memiliki tujuan untuk menggubah suatu bangunan, bagi manusia secara individu atau kelompok agar dapat menjalankan berbagai jenis aktivitas dari yang sederhana sampai yang kompleks dengan nyaman. Dalam konteks perancangan tipologi kafe, dari hasil analisis dapat disimpulkan bahwa hal-hal yang harus diperhatikan agar gubahan ruang yang dibuat dapat menghasilkan aspek kebetahan adalah: kesesuaian desain dengan tema yang diusung, ketepatan pemilihan material, ketepatan pengolahan material menjadi elemen-elemen interior, dan pemikiran out of the box. Terutama karena saat ini 
sedang marak fenomena swafoto, sehingga desain yang unik dan eye catching menjadi salah satu kunci utama terjadinya faktor kebetahan dan motivasi kunjungan ulang.

Fenomena café society yang saat ini sedang berkembang, khususnya di Bandung ternyata juga bergantung pada keilmuan desain interior. Keberhasilan desainer interior menerjemahkan sebuah konsep desain menjadi ruang-ruang tiga dimensi yang menarik dan memiliki faktor attraction menjadi salah satu alasan utama motivasi seseorang berkunjung ke kafe. jika hal ini terus berlangsung, maka transformasi ruang kota akan berjalan sangat cepat dan harus pula tetap dilihat perkembangannya agar dapat terjadi perubahan berkesinambungan yang tetap sesuaidengan aturan tata kota.

Penulis sadar terdapat banyak kekurangan dalam penelitian ini. Mengacu pada topik yang dituliskan oleh Farasa, 2015 saran untuk penelitian ke depan adalah untuk mencoba mencari kesamaan tipologi kafe dari segi bangunannya (denah, bentukan, langgam, tahun dibuat, penggayaan, dan lainnya) dan juga mengambil sampel yang lebih banyak agar hasil diseminasi penelitian dapat menjadi lebih valid.

\section{Referensi}

Creswell, J. W. (2002). Research Design: Qualitative, Quantitative, and Mixed Methods Approaches. Second Edition, Sage Publications, International Education and Professional Pubisher.

Farasa, N dan Kusuma, H.E. (2015). Faktor-Faktor yang Mempengaruhi Kebetahan di Kafe: Perbedaan Preferensi dan Gender. Prosiding Temu Ilmiah Ikatan Peneliti Lingkungan Binaan (IPLBI) 2015, 1-6.

Scanell, L dan R. Gifford (2010). Defining Place Attachment: A Tripartite Organizing Framework. Journal of Environmental Psychology 30 p.1-10. Elsevier.

Haristianti,V, Kurniatai, F, dan Syahriah D.R (2015). Kinerja Ruang Publik Kampus Ditinjau dari Faktor Attraction. Studi Kasus: Lapangan Campus Center Timur ITB. Prosiding Temu Ilmiah Ikatan Peneliti Lingkungan Binaan (IPLBI) 2015, E 095-100.

Haristianti, V (2016). Peran Kafe Terhadap Pembangunan Conservation District, Studi Kasus: Kafe di Kawasan Braga, Bandung. Prosiding Temu Ilmiah Ikatan Peneliti Lingkungan Binaan (IPLBI) 2016, A 130-134.

Kumar, R. (2005). Research Methodology: A Step by Step Guide for Beginner. London, Sage Publication.

Kusuma, H.E (2009). Memilih Metode Analisis Kuantitatif untuk Penelitian Arsitektur. Seminar Nasional Metodologi Penelitian Arsitektur. Semarang: Universitas Dipenogoro.

Rachman R.A dan Kusuma, H.E. (2014). Definisi Kebetahan dalam Ranah Arsitektur dan Lingkungan Perilaku. Prosiding Temu Ilmiah Ikatan Peneliti Lingkungan Binaan (IPLBI) 2014, A 55-60.

Rubiah, H. Ternyata Jalan Riau Menyimpan Sejarah Panjang, Begini Ceritanya, data diperoleh melalui situs internet: $\quad$ https://jabar.tribunnews.com/2019/01/05/ternyatajalanriau-menyimpan-sejarah-panjangbegini-ceritanya?page $=2$. Access Date 25/01/2020.

Susanti, A (2017). Kajian Tipologi Konfigurasi Sonasi dan Furniture pada Interior Coffee Shop di Denpasar. Jurnal Arsitektur, 1(1), 15-16

Sireki, Talenta., dan Wibisono, B. (2020). Karakteristik Third Place dan Tipologi Kafe di Yogyakarta.Tata Loka, 22 (3), 438-440

Tinamei, A. (2006). A Semiotic Approach to the Cafe Society Phenomenon. International Seminar on Urban Culture/ Arte-Polis: Creative Culture and the Making of Place Proceedings, III 98- 107.

Widiastuti, I. (2006). Informality in Urban Spaceas Identity Creating Image of Bandung as Heaven of Food and Shopping. International Seminar on Urban Culture/ Arte-Polis: Creative Culture and the Making of Place Proceedings, III 126-133 